\title{
Orthogeriatric care: improving patient outcomes
}

Francisco José TarazonaSantabalbina ${ }^{1,2}$

Ángel Belenguer-Varea ${ }^{1,2}$

Eduardo Rovira ${ }^{1,2}$

David Cuesta-Peredó',2

'Geriatric Medicine Unit, Internal Medicine Department, Hospital Universitario de la Ribera, ${ }^{2}$ Medical School, Universidad Católica de Valencia San vicente Mártir, Valencia, Spain

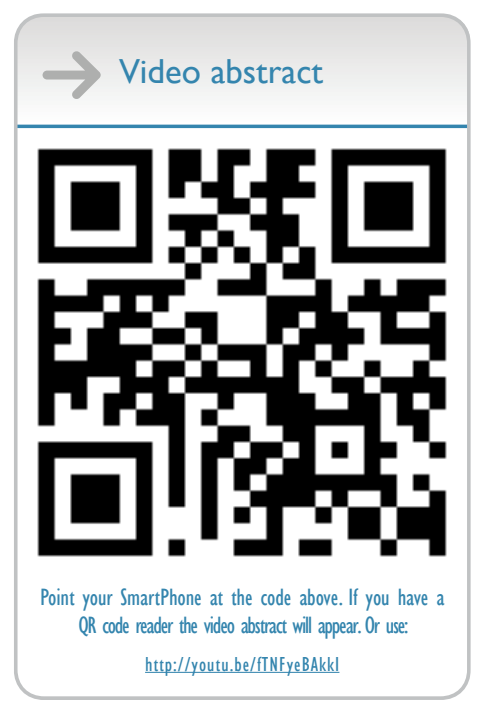

Correspondence: Francisco José Tarazona-Santabalbina Hospital Universitario de la Ribera, Carretera de Corbera, E46600 Alzira, Valencia, Spain

Tel +34962458387

Fax +34 962458 I5।

Email fjtarazona@hospital-ribera.com
This article was published in the following Dove Press journal:

Clinical Interventions in Aging

24 June 2016

Number of times this article has been viewed

Abstract: Hip fractures are a very serious socio-economic problem in western countries. Since the 1950 s, orthogeriatric units have introduced improvements in the care of geriatric patients admitted to hospital because of hip fractures. During this period, these units have reduced mean hospital stays, number of complications, and both in-hospital mortality and mortality over the middle term after hospital discharge, along with improvements in the quality of care and a reduction in costs. Likewise, a recent clinical trial has reported greater functional gains among the affected patients. Studies in this field have identified the prognostic factors present upon admission or manifesting themselves during admission and that increase the risk of patient mortality or disability. In addition, improved care afforded by orthogeriatric units has proved to reduce costs. Nevertheless, a number of management issues remain to be clarified, such as the optimum anesthetic, analgesic, and thromboprophylactic protocols; the type of diagnostic and therapeutic approach best suited to patients with cognitive problems; or the efficiency of the programs used in convalescence units or in home rehabilitation care. Randomized clinical trials are needed to consolidate the evidence in this regard.

Keywords: hip fractures, geriatric assessment, orthogeriatric care, recovery of function, mortality

\section{Introduction}

Osteoporotic hip fractures are one of the main health problems in geriatric patients. A total of 1.3 million hip fractures were diagnosed in $1990,{ }^{1}$ and this figure is expected to increase to over 6 million by $2050 .^{2}$ A total of $80 \%$ of the fractures in women and $50 \%$ of those in men occur at over 70 years of age. ${ }^{3}$ Ninety percent of the fractures are a result of falls from standing height. ${ }^{4}$ The mortality rate can reach $10 \%$ during admission in hospital and 30\% after 12 months. ${ }^{5,6}$ Only 50\% of those who survive recover the functional level they had before the accident ${ }^{7,8}$ and $25 \%$ of the patients who were independent before the fall require admission to a home for the elderly. ${ }^{9}$ The estimated socio-economic costs represent $0.1 \%$ of the global health care costs worldwide, reaching $1.4 \%$ in the more developed countries. ${ }^{1}$ The mean age of patients with hip fracture ${ }^{10}$ and the presence of comorbidity ${ }^{11}$ are the main reasons warranting orthogeriatric comanagement of these individuals, which reduces the risk of perioperative complications, functional deterioration, and mortality. ${ }^{12}$

In this regard, geriatric joint trauma management units were introduced in the UK in the mid-twentieth century. ${ }^{13}$ However, it is over the last 20 years that the design and implementation of coordinated perioperative models have increased. ${ }^{14}$ Such coordinated patient care has been shown to reduce in-hospital complications, ${ }^{15,16}$ hospital stay and readmissions, ${ }^{17}$ disability, and in-hospital mortality. ${ }^{16}$

A recent editorial ${ }^{18}$ considers that geriatric medicine improves our knowledge of the extra-traumatology factors that complicate the patient's course and influence the 
outcome of treatment. The clinical and social complexity of elderly patients demands close cooperation among the different professionals, with a different approach to management from that applicable to younger individuals. ${ }^{19}$ In addition to the traditional goals of the orthogeriatric team, there is another crucial objective: patient enrollment in the most appropriate rehabilitation program in order to reduce the need for institutionalization and facilitate functional recovery and reintegration to the regular social setting of the patient. ${ }^{19}$

In this regard, correct assessment of the previous functional situation and maximum recovery of that situation are of vital importance. The high prevalence of disability following fracture can modify the natural patient referral process after hospital discharge ${ }^{20}$ and in this sense the management plan does not conclude with hospital discharge but rather comprises the continuation of patient care beyond the inhospital process. The actions of the orthogeriatric team thus extend beyond the hospital setting, expanding the benefits of integral geriatric care. ${ }^{19}$

It is in the UK where the role of orthogeriatrics has been best defined to date, largely as a result of the development of the best practice tariff, introduced in 2010 with the purpose of improving the management of patients with hip fracture. ${ }^{21}$ Presurgical and postsurgical cognitive assessments were subsequently also included. ${ }^{22}$ The National Institute for Health and Care Excellence drafted a document on the quality care of patients with hip fracture, underscoring a series of highquality indicators to be complied with in order to boost efficiency in the management of patients with hip fracture. ${ }^{23}$

The orthogeriatric care models agree on the suitability of care provided by multidisciplinary teams with knowledge of geriatrics, the advisability of early surgery, the need for a case manager (in this case a geriatrician) throughout the whole process, pain control, avoidance of the appearance or worsening of geriatric syndromes, and correct continuity of care after hospital discharge, thus attempting to recover the functional condition before the time of fracture. ${ }^{24}$ Such orthogeriatric management has been validated by a recent meta-analysis. ${ }^{25}$

However, there are still issues requiring study and analysis, such as the optimum thromboprophylactic protocols, correct analgesic regimens, assessment and treatment of cognitive deterioration and nutritional conditions during the in-hospital period, improvement of patient mobility, and postsurgical rehabilitation. ${ }^{24}$

The present review aims to offer answers to some of these uncertainties regarding the orthogeriatric care of patients with hip fracture and attempts to clarify which measures have improved the management outcomes.

\section{Methods}

The present review was carried out by conducting an electronic search in OVID (Medline and Embase), combining the following MeSH keywords: "hip fractures" and "geriatric assessment", combined with "perioperative management" and "orthogeriatric care". The search was limited to publications in the last 5 years; in English, Spanish, and French; and in human subjects. A total of 177 articles were obtained, of which 86 were finally selected. The MeSH construction [Hip fractures] AND ([Geriatric assessment] OR "perioperative management") OR "orthogeriatric care" OR "geriatric syndromes") was used. Some additional instructions were added for certain specific objectives where necessary. In 14 cases, supplementary information was obtained in the form of references of the selected articles. Details of the evaluation and selection process of the items are shown in Figure 1.

The articles were selected by four investigators based on the following inclusion criteria: randomized clinical trials, cohort studies, case-control studies, observational studies,

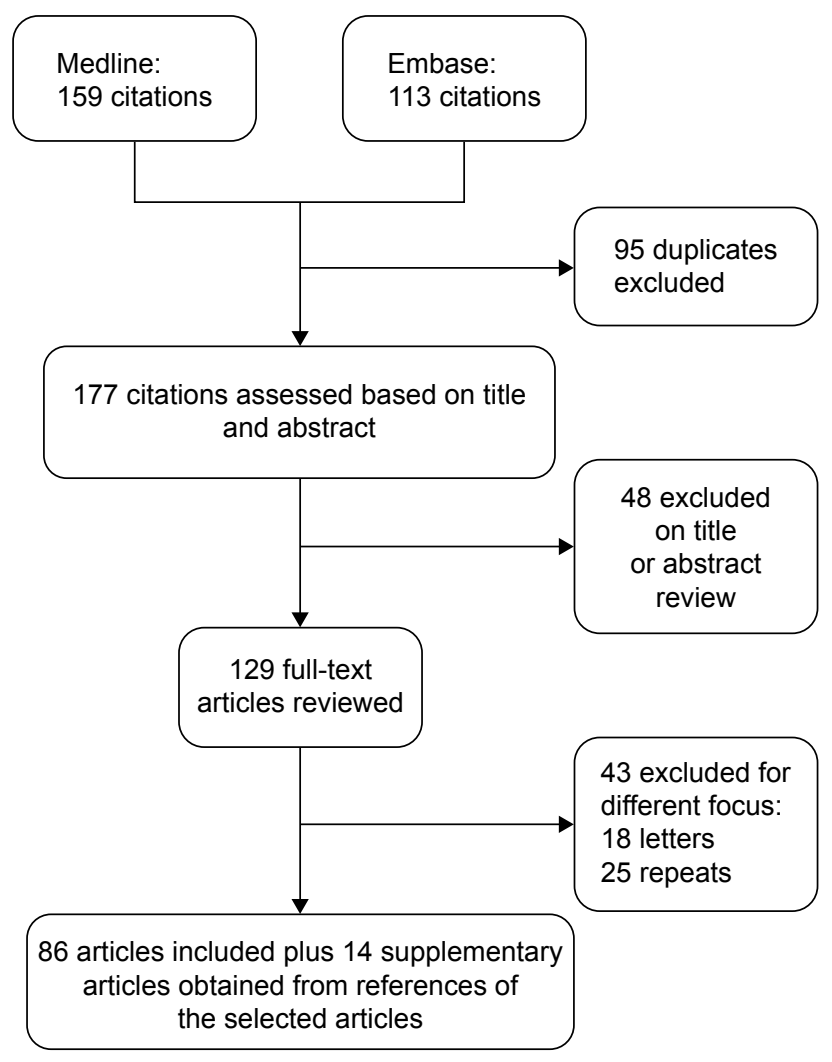

Figure I Flow chart study selection procedure used in literature search. 
and before-after analyses in orthogeriatric units; population: geriatric patients with proximal femoral fracture; intervention: orthogeriatric treatment begun perioperatively; and outcomes: surgical delay, length of hospital stay, prognostic factors and mortality, functional recovery, geriatric syndromes, perioperative care such as renal function, anemia, second hip fracture and complications, surgical treatment, and costs.

The exclusion criteria were letters to the Editor, case reports, articles with no available abstract or those with only the abstract published, and studies meeting the inclusion criteria but with $\geq 50 \%$ of the study sample aged under 65 years (ie, predominantly non-geriatric). All the articles were reevaluated by the authors of the review, and final inclusion was restricted to those of sufficient quality to afford information pertinent to the objectives of this review.

The outcome measures examined were mortality, length of hospital stay, functional status, medical complications, destination after discharge, functional recovery, secondary prevention treatments, and readmissions.

\section{Results}

The efficiency and benefits of orthogeriatric care ${ }^{14}$ indicate that the aforementioned multidisciplinary approach should be generalized. However, this patient care model has still not been implemented in many hospitals. The centralization of information in the form of national registries would facilitate the comparison of results between the traditional approach and orthogeriatric management and would allow us to define the benefits of the different implemented models. ${ }^{18}$ The variants of the model coincide in underscoring the need for early geriatric clinical care and early surgical management, ${ }^{26}$ since both these measures can reduce inhospital morbidity-mortality.

A meta-analysis of 35 independent studies recruiting 191,873 patients described greater survival among patients who underwent early surgery (odds ratio [OR] 0.74; 95\% confidence interval $[\mathrm{CI}] 0.67-0.81 ; P<0.001)$. Authors calculated odds of death with cutoff of surgical delay in 24 hours (OR 0.74 [95\% CI 0.62-0.87; $P<0.001]$ ) and 48 hours (OR 0.75 [95\% CI 0.68-0.81; $P=0.031]$ ). There was no difference in survival when the surgical delay cutoff was established in less than 12 and 96 hours, respectively. ${ }^{27}$ (The most relevant results included in this review are summarized in Table 1.)

Previously, Vidan et $\mathrm{al}^{28}$ found delays in surgery to be associated with increased mortality from day 6 after fracture.
A meta-analysis of 16 observational studies $(n=13,478)$ in turn showed surgery in the first 24 hours, versus in the first 72 hours, to reduce patient mortality. ${ }^{29}$

The main cause of surgical delays is the lack of available operating rooms. ${ }^{28}$ Clinical stabilization, based on clinical recommendations and guidelines, on the part of the orthogeriatric teams can contribute to reduce such delays, increasing comorbidity diagnostic precision, ${ }^{30}$ since the second most important cause of surgical delays is the presence of medical complications. ${ }^{28}$

Considering the need for early preoperative medical evaluation to avoid clinical contraindications to surgery, four reviews have recommended ${ }^{31-34}$ comprehensive geriatric assessment with the purpose of adequately estimating perioperative risk and preventing complications. Likewise, in emphasizing the importance of early clinical care and homogeneity of the management objectives, we consider that the orthogeriatric clinical protocols should also implicate the emergency care service.

As has been pointed out by an editorial, ${ }^{14}$ another important advantage of such orthogeriatric care is the shortening of hospital stay, despite a lack of analyses by subgroups in different studies, based on the case mix referred to comorbidity and prior functional and social condition. Such shortening of stay is the result of continuously improving quality of care, reducing patient stay in emergency service, facilitating structured management, and incorporating new measures based on evidence. ${ }^{35}$

\section{Geriatric syndromes}

\section{Delirium}

The incidence of delirium in elderly individuals with hip fracture varies between $38 \%$ and $61 \%$ and is greater in patients with dementia. ${ }^{36}$ In subjects without prior dementia or delirium, the incidence of delirium and nonspecific cognitive dysfunction is lower $(21.3 \%),{ }^{37}$ and in such cases hypoactive delirium is the most common presentation. ${ }^{38}$ Likewise, delirium is a risk factor for poorer survival 6 months after hospital discharge. ${ }^{38}$

The published interventions for the prevention and treatment of delirium combine different strategies, based on a multifactorial approach or proactive geriatric consultation and follow-up..$^{39}$ Different studies have reported a decrease in the incidence of delirium in the intervention group, ${ }^{40,41}$ and even a shorter duration of delirium. ${ }^{42}$ Data from the subanalysis of a clinical trial, ${ }^{43}$ only including patients with delirium upon admission, described a significant decrease 


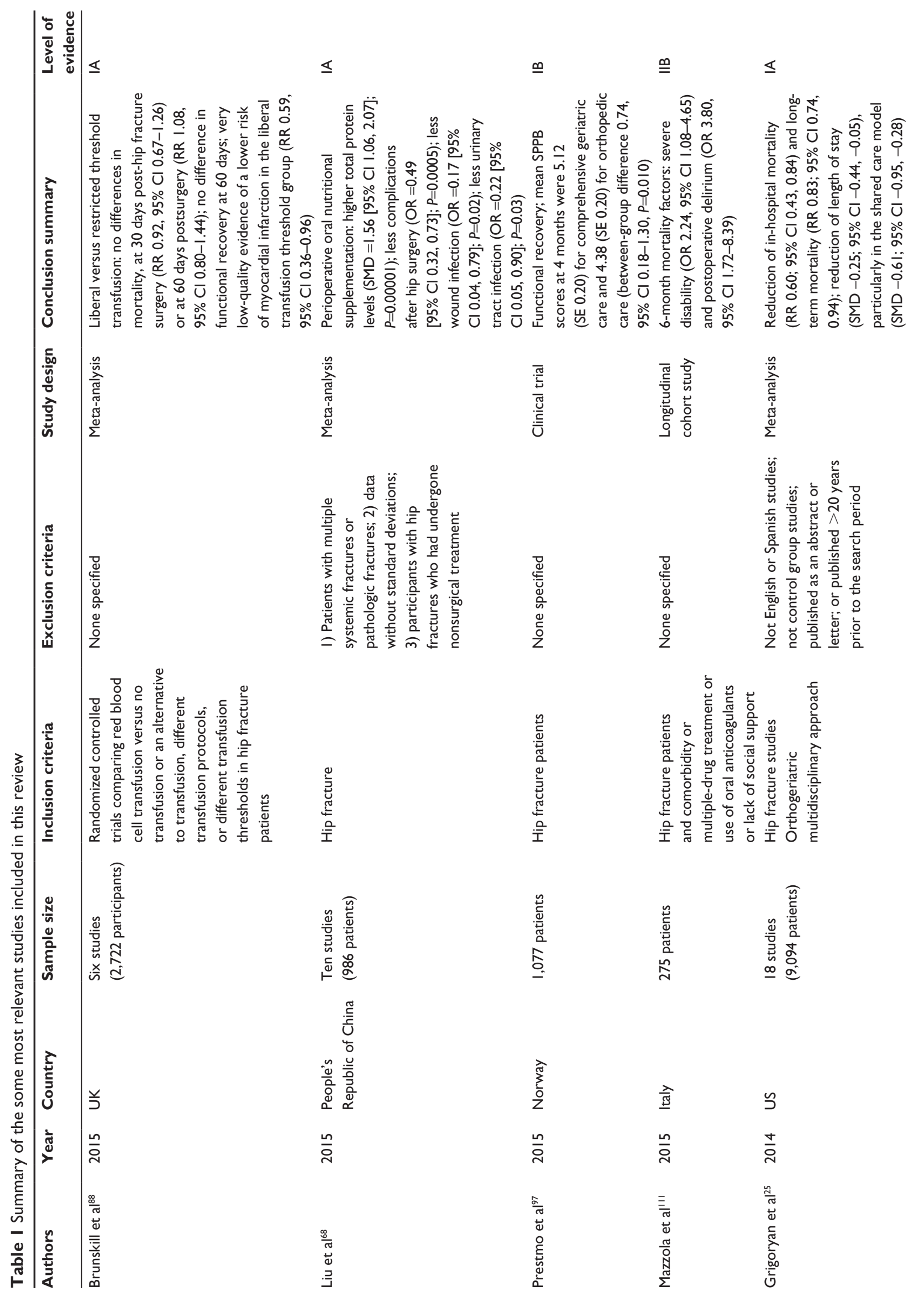



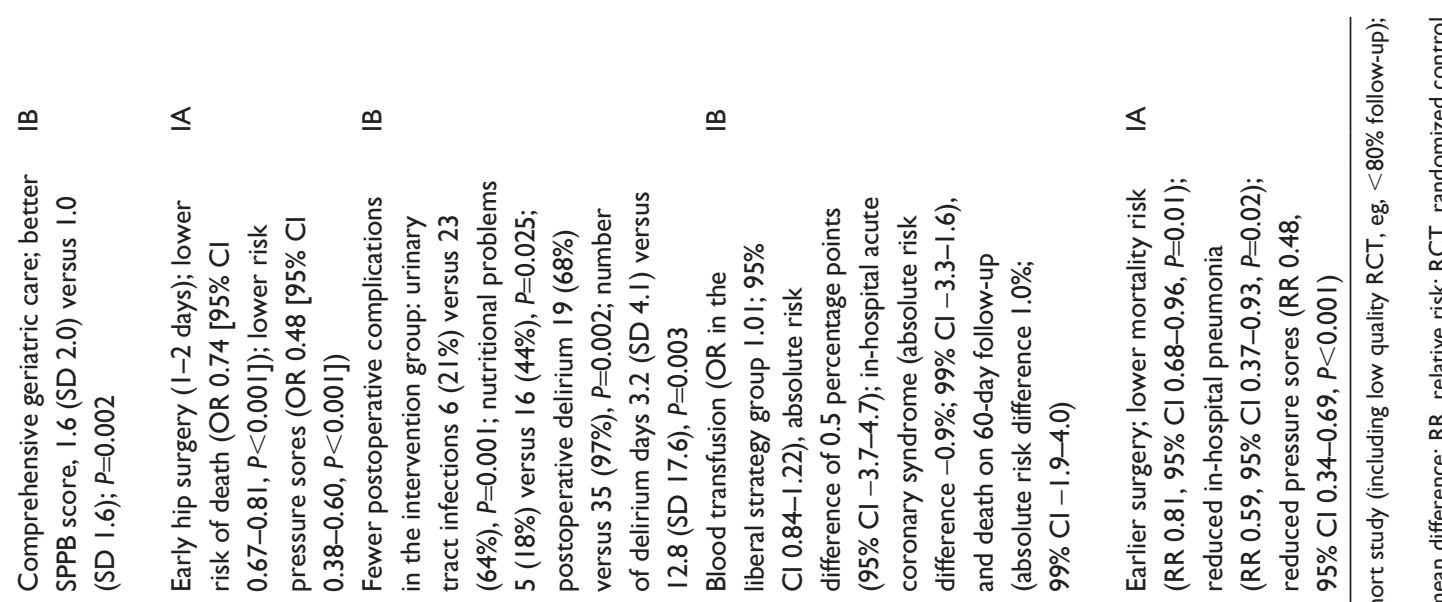

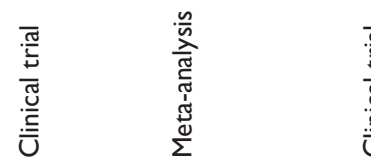
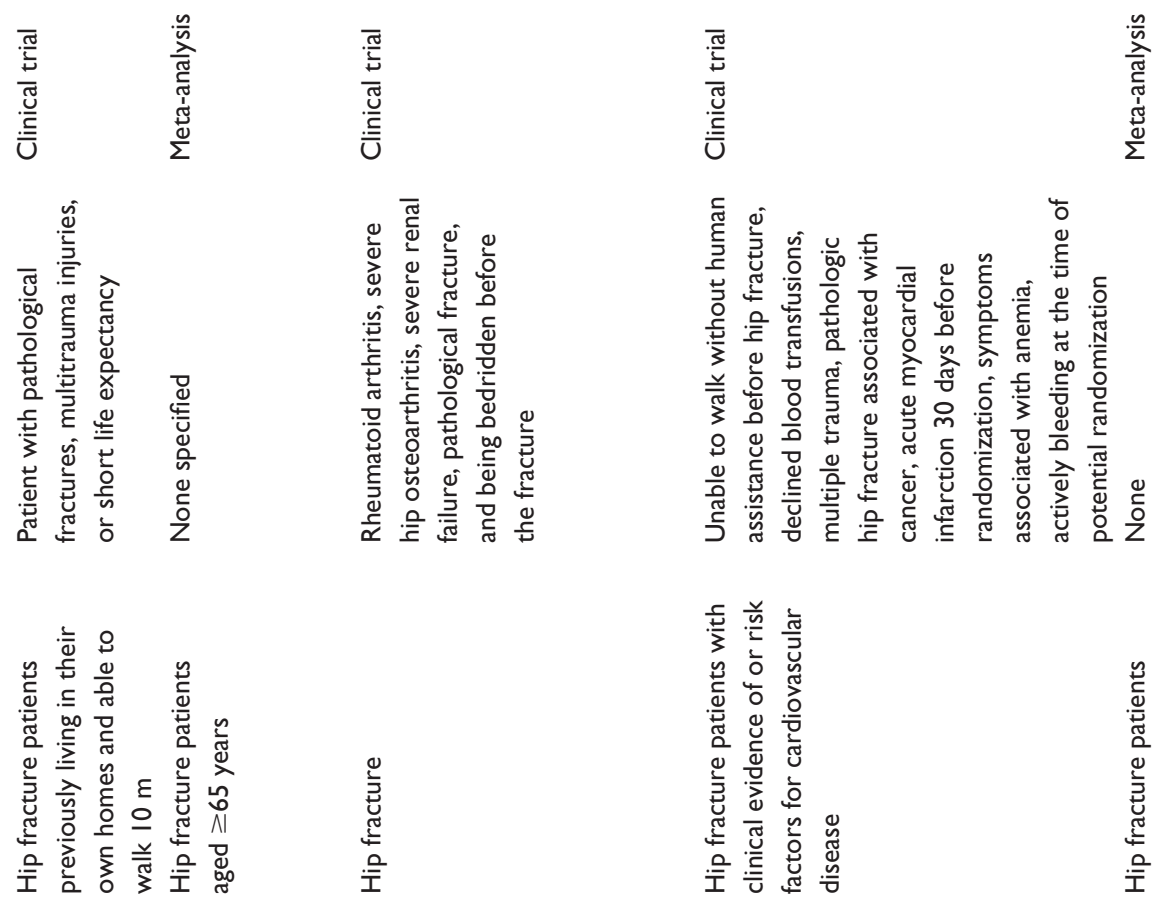

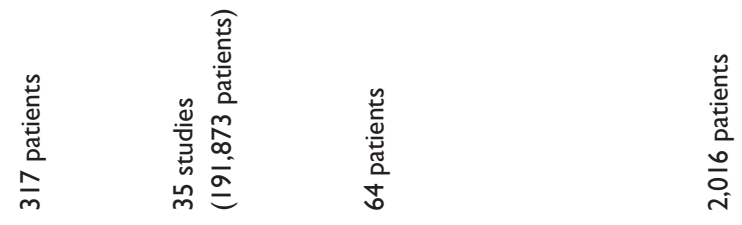
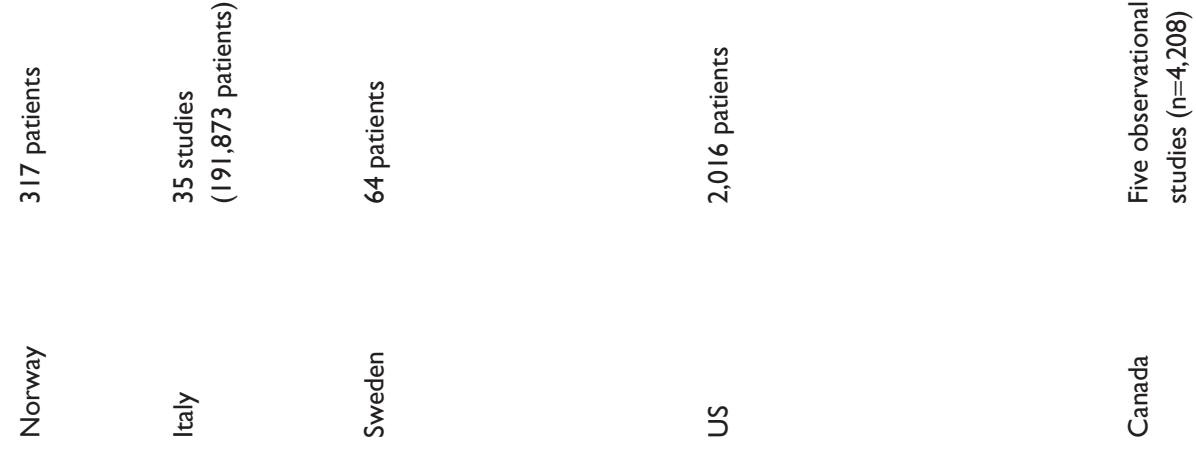

离

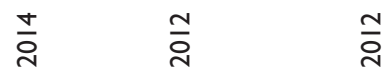

$\overline{\bar{\alpha}}$

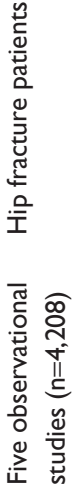

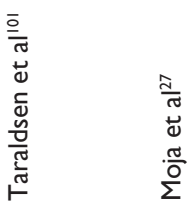

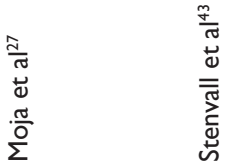

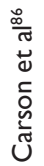

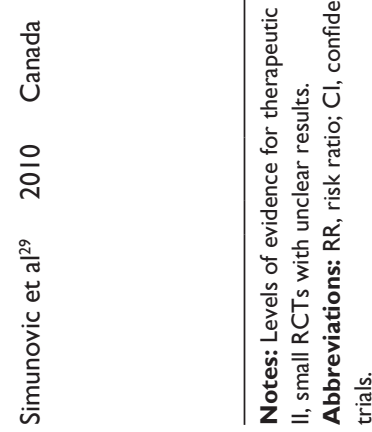


in postoperative delirium in the orthogeriatric care group, together with a significant decrease in the incidence of urinary tract infections, nutritional problems, and the incidence of falls.

The incidence of delirium can be lowered by assigning patient rooms close to the common areas and rehabilitation facilities, and this measure, moreover, improves patient comfort and contributes to shortening hospital stay. ${ }^{44}$ Proactive geriatric care, electrolyte normalization and adequate hydration, oxygenation, pain and constipation control, drug monitoring with reviewing of the psychoactive medication used, and early mobilization all contribute to reducing the incidence of delirium. ${ }^{45}$

\section{Cognitive impairment}

Forty percent of all elderly people admitted because of hip fracture suffer from some degree of cognitive impairment. ${ }^{46}$ Functional recovery of patients with cognitive impairment and hip fracture is variable. ${ }^{43}$ In this regard, a systematic review has found similar functional gains in patients with and without mild or moderate cognitive impairment. ${ }^{47}$ In a cohort of 314 elderly patients admitted due to hip fracture, in which $43 \%$ suffered from cognitive impairment, walking capacity prior to fracture, the presence of pressure ulcers (bed sores), and the incidence of delirium were found to be more robust predictors of functional recovery than the degree of cognitive impairment. ${ }^{48}$ In a study published by our group ${ }^{49}$ on 1,258 patients with hip fracture, $30 \%$ were seen to have dementia prior to admission. The patients without cognitive impairment showed higher walking rates at discharge and after 6 and 12 months than the patients with mild, moderate, or severe dementia - independently of age, prior Barthel score, sex, Charlson score, or presence of delirium upon admission. The mortality rate at discharge and after 1, 6, and 12 months was also lower among the patients without dementia than among those with mild, moderate, or severe dementia. In the adjusted model, the differences remained significant only in the group with severe dementia. Patients with cognitive impairment obtain benefit from rehabilitation programs in orthogeriatric units that use a specific multidisciplinary approach and in rehabilitation centers after hospital discharge..$^{50}$

\section{Depression}

The presence of depression and its treatment increase the risk of fractures ${ }^{51}$ and have a negative impact on functional recovery and mortality. Moderate or severe depression upon admission results in poorer recovery at discharge, ${ }^{52}$ and is predictive of a considerable increase in the institutionalization and mortality rates after 12 months. ${ }^{53,54}$ Depression in patients with hip fracture has been associated with reductions in plasma dehydroepiandrostenedione and increases in cortisol levels, accelerating progression toward fragility. The cortisol and dehydroepiandrostenedione ratio is higher in individuals with hip fracture than in healthy elderly subjects, and this ratio is a possible mediator between hip fracture and health condition. A study has found post-hip fracture depression to be associated with poorer functional recovery and slower walking speed. ${ }^{55}$ The screening of depression in these patients could contribute to ensuring better management of the problem and minimizing its negative impact on patient recovery.

\section{Constipation}

Constipation is common among patients admitted due to hip fracture and is related to immobilization, loss of intimacy, and use of certain drug substances. In turn, constipation is associated with postoperative complications, a longer mean stay, and higher costs. Nevertheless, the condition is often underdiagnosed. ${ }^{56}$ Approximately $70 \%$ of all patients develop constipation during the first postoperative days, and $62 \%$ continue to suffer from the problem up to 1 month after surgery. ${ }^{57}$ The recommended options to prevent constipation comprise the use of laxatives, an increase in fiber and liquid intake, and the favoring of mobility. ${ }^{58}$

\section{Malnutrition}

Protein-calorie malnutrition increases the risk of falls and fractures. Moreover, the nutritional condition of elderly people with hip fractures tends to worsen during admission, and malnutrition is common among hip fracture patients, ${ }^{59}$ thereby increasing the risk of complications, mean stay, mortality, and costs. Furthermore, malnutrition is more frequent in elderly individuals with greater comorbidity and functional and cognitive deterioration. ${ }^{60}$ The detection of malnutrition is important, though the application of rapid detection tools for this purpose is insufficient. ${ }^{61}$ Nutritional intervention in the postoperative period of these patients does afford clinical benefits in the form of a shorter stay, fewer complications, lesser mortality, and more stable quality of life. ${ }^{62-66}$ Exhaustive care in the home after hospital discharge, with the inclusion of nutritional measures, significantly improves the nutritional condition of the patients and their functional capacity. ${ }^{67} \mathrm{~A}$ recent meta-analysis on perioperative oral nutritional supplementation in elderly patients with hip surgery based on ten studies described a positive effect on serum total protein levels, with a decrease in the number 
of complications and wound, respiratory and urinary tract infections, though no significant differences in mortality were recorded. ${ }^{68}$

Swallowing problems can result in denutrition, dehydration, aspiration pneumonia, a longer stay in hospital, and increased costs. ${ }^{69}$ In one study, $27.7 \%$ of the patients who previously had no swallowing problems developed oropharyngeal dysphagia 72 hours after hip fracture surgery - this condition being associated with the presence of prior neurological and/or respiratory illness, postoperative delirium, age, and previous institutionalization. ${ }^{70}$ The development of dysphagia in the postoperative period is of multifactorial origin, and screening measures should be adopted, particularly in more fragile patients.

\section{Urinary retention and urinary incontinence}

In a recent study, ${ }^{71} 51.3 \%$ of the patients admitted because of hip fracture suffered urinary retention with the need for bladder catheterization - retention in turn being associated with the presence of diabetes, urinary infection, and delirium. Hip fracture likewise has been related to an increased prevalence of urinary incontinence (UI). ${ }^{72}$ Incontinence after surgery has been associated with the use of drugs and anesthetic agents, appearance of urinary retention and/or infection, constipation, and difficulty in gaining access to bathroom, among other factors. The presence of UI can have a negative impact on functional recovery. ${ }^{73}$ In one study, ${ }^{74}$ $11 \%$ of the patients presented incontinence 72 hours after surgery, and the problem was associated with delirium, urinary infection, cognitive impairment, and depressive symptoms. Furthermore, 12 months after the operation, the patients had poorer function and greater institutionalization and mortality rates than the patients without UI. The probability of developing incontinence during hospitalization has been associated with previous institutionalization, delirium, previous need for medical devices, and walking dependency. ${ }^{75}$ At 6 months after discharge, the prevalence of incontinence remains high, though after 2 years of follow-up it has been shown that UI, together with personal hygiene and eating, is one of the basic aspects that is most amenable to improvement. ${ }^{76,77}$ UI should be taken into account by orthogeriatric teams, though the evidence of the efficacy of specific management during admission is not convincing. ${ }^{78}$

\section{Pressure sores}

In a study carried out in several European countries, the prevalence of pressure sores (PSs) in elderly people admitted due to hip fracture was $10 \%$ upon admission and $22 \%$ at discharge - most of them being of grade I. The factors associated with PSs at discharge were patient age over 70 years, dehydration, moist skin, total Braden score, nutritional status, existence of sensory defects, and presence of diabetes and/or lung disease. ${ }^{79}$ Other studies have also reported an association with delays in surgery; ${ }^{80}$ moreover, the presence of such ulcers prolongs hospital stay. ${ }^{81}$ The use of appropriate clinical pathways in patient care can reduce the incidence of PSs by more than $50 \%{ }^{82}$ Devices for elevating the heels and the use of pressure-redistributing mattresses have been found to be effective in some studies, ${ }^{83}$ though other publications with low PS incidence have failed to observe benefits. ${ }^{84}$ Surgical delay is related to the incidence of PSs, and a meta-analysis mentioned showed a reduction of risk of PSs related to shorter surgical delay (OR 0.48, $\left[95 \%\right.$ CI $\left.\left.0.38-0.60 ; I^{2}=0 \%\right]\right) .^{27}$

\section{Perioperative care}

\section{Renal function}

Patients with low glomerular filtration rates present with increased comorbidity, lower hemoglobin $(\mathrm{Hb})$ concentrations upon admission, longer surgical delays, and greater incidence of delirium. At hospital discharge, individuals with higher glomerular filtration rates yield higher motor Functional Independence Measure (FIM) scores. Likewise, low plasma urea levels upon admission have been associated with greater recovery of the motor FIM score and higher total score at discharge. ${ }^{85}$

\section{Anemia}

The management of anemia in geriatric patients with hip fracture is subject to controversy. Upon admission to hospital, $\sim 80 \%$ of all fracture patients have $\mathrm{Hb}$ values below $11 \mathrm{~g} / \mathrm{dL}$. A clinical trial ${ }^{86}$ randomized patients with hip fracture and anemia to two transfusion thresholds ( 8 and $10 \mathrm{~g} / \mathrm{dL}$, respectively) and no differences were observed in mortality after 30 days or in walking capacity after 60 days. Conversely, Gregersen et al ${ }^{87}$ randomized patients to two transfusion thresholds in a clinical trial: restrictive $(\mathrm{Hb}<9.7 \mathrm{~g} / \mathrm{dL})$ and liberal $(\mathrm{Hb}<11.3 \mathrm{~g} / \mathrm{dL})$. There were no functional improvement differences, but 30-day and 90-day mortality was higher with the restrictive strategy, hazard ratio $=2.4(95 \%$ CI 1.1 $-5.2 ; P=0.03)$ and hazard ratio $=2.0$ (95\% CI 1.1-3.6; $P=0.01)$, respectively. A Cochrane review and meta-analysis ${ }^{88}$ of 2,722 patients found no differences when two thresholds for red blood cell transfusion were compared: a liberal strategy to maintain a $\mathrm{Hb}$ concentration of usually $10 \mathrm{~g} / \mathrm{dL}$ versus a more restrictive strategy based 
on symptoms of anemia or a lower $\mathrm{Hb}$ concentration, usually $8 \mathrm{~g} / \mathrm{dL}$. There was no evidence of a difference between a liberal versus restricted threshold transfusion in mortality at 30 days post-hip fracture surgery or at 60 days postsurgery; neither was there in functional recovery at 60 days. There was low quality evidence of no difference between the transfusion thresholds in postoperative morbidity for the following complications: thromboembolism, stroke, wound infection, respiratory infection (pneumonia), and new diagnosis of congestive heart failure. There was very low-quality evidence of a lower risk of myocardial infarction in the liberal compared with the restrictive transfusion threshold group (risk ratio 0.59, 95\% CI 0.36-0.96; three trials; 2,217 participants). Authors concluded that the available evidence does not support the use of liberal red blood cell transfusion thresholds based on a $10 \mathrm{~g} / \mathrm{dL} \mathrm{Hb}$ trigger. Intravenous iron ${ }^{89}$ has not been found to reduce the transfusion rate, hospital stay, complications, or infections.

\section{Second hip fracture}

Many studies have shown that osteoporosis is underdiagnosed and hence undertreated in patients with hip fracture. In this regard, hip fracture represents an opportunity for starting early prevention of new fractures. ${ }^{90}$ Patients who have suffered hip fracture are at a greater risk of new falls and fractures than the general population. Low scores ( $\leq 14$ points) on the Norton scale, used to evaluate the risk of PSs, are associated with increased mortality, greater risk of postoperative complications such as urinary infections, and up to threefold higher risk of new falls..$^{91,92}$ In a populationbased 7-year follow-up study of 87,415 patients with a first hip fracture, the incidence of a second hip fracture was $9.2 \%$ - the annual risk in patients aged 75 years or older being $4.1 \% .{ }^{93}$ In this study, the presence of obesity, diabetes, arterial hypertension, dyslipidemia, cerebrovascular disease, and/or vision problems was associated with an increased risk of a second fracture, while bisphosphonate therapy was associated with a lesser risk. The most common strategies for avoiding such situations include changes in lifestyle, drug treatment, and prevention of falls. ${ }^{94}$

\section{Functional recovery}

The fundamental aim of orthogeriatric units is to restore the previous independence of the patient. ${ }^{33}$ Each day of immobilization makes it more difficult to reach this aim due to diminished muscle mass and strength, increased joint stiffness and pain, and loss of confidence - with the consequent fear of falls. A recent meta-analysis ${ }^{25}$ has evidenced shortened hospital stay and lesser mortality in orthogeriatric units, with no differences in functional recovery. Another metaanalysis ${ }^{95}$ likewise observed no improvement in the long-term functional outcomes in the orthogeriatric models.

A retrospective cohort study of 1,257 patients with hip fracture recorded a $68 \%$ community reincorporation rate after rehabilitation. Likewise, they presented fewer comorbidities, shorter hospital stay, and better functional and cognitive conditions. Use of the motor FIM score made it possible to predict which patients could return home. ${ }^{96}$

A randomized clinical trial ${ }^{97}$ found functional gain to be greater in the orthogeriatric care group than among the patients receiving routine trauma care during the follow-up period. At 1 month after discharge, the patients in the orthogeriatric care group presented with a higher Short Physical Performance Battery score; after 4 months this was also accompanied by better cognitive function, greater independence, lesser fear of falls, and better quality of life. In addition, after 12 months, improved scores were observed on the Geriatric Depression Scale. The mean hospital stay was longer in this group, with a larger percentage of patients sent home after hospital discharge.

Early mobilization after the operation is essential since it reduces the incidence of delirium and pneumonia, improves function, and is associated with lesser mortality. ${ }^{98}$

However, a few studies have examined the relationship between inpatient bed rest and functional outcomes. A prospective cohort study of 532 patients examined the relationship between immobility, function, and mortality in patients with hip fracture. Such patients experienced an average of 5.2 days of immobility. Compared with patients with a longer duration of immobility (ie, at the 90th percentile) in adjusted analyses, patients at the 10th percentile of immobility had a lower 6-month mortality $(-5.4 \%$; $95 \% \mathrm{CI}-10.9 \%$ to $-1.0 \%)$ and a better FIM score for locomotion (0.99 points; $95 \%$ CI $0.3-1.7$ points). The adverse association of immobility was strongest in patients using personal assistance or supervision with locomotion at baseline (difference in 6-month mortality between the 90th and 10th percentile of immobility was $-17.1 \%[P=0.004]$ for this group and only $1.2 \%[P=0.38]$ for patients independent in locomotion at baseline). ${ }^{99}$

A study on early mobilization investigated the effect of early ambulation (EA) after hip fracture surgery on patient and hospital outcomes. Randomization was either EA (first walk postoperative day 1 or 2 ) or delayed ambulation (first walk postoperative day 3 or 4). At 1 week postsurgery, patients in the EA group walked further distance than those in the delayed ambulation group (34.70 $\mathrm{m}$ [range, $r=5-103$ ] 
versus $29.71 \mathrm{~m}[r=0-150], P=0.03)$ and required less assistance to transfer $(26.3 \%$ versus $50 \%, P=0.009) .{ }^{100}$

A subanalysis of a randomized controlled trial, the Trondheim Hip Fracture Trial, compared physical behavior and function during the first postoperative days for hip fracture patients managed with comprehensive geriatric care with those managed with orthopedic care. The comprehensive geriatric care participants had significantly more upright time (mean 57.6 versus 45.1 minute, $P=0.016$ ), higher number of upright events (24.1 [SD $=22.1$ ] versus 19.0 [SD $=16.5$ ], $P=0.005)$, and better Short Physical Performance Battery scores (1.6 [SD $=2.0$ ] versus 1.0 [SD $=1.6], P=0.002)$ than the orthopedic care participants. ${ }^{101}$

\section{Surgical treatment}

In patients with subcapital fractures, total arthroplasty versus hemiarthroplasty offers more lasting functional results and better pain control, despite a greater risk of complications (mainly luxation). ${ }^{102}$ Surgery must take into account the patient's mental condition, social situation, level of dependency, and quality of bone in deciding the type of operation. Minimally invasive surgical techniques reduce bleeding and transfusion needs versus conventional surgery. ${ }^{103}$ In a recent meta-analysis, the minimally invasive dynamic hip screw technique in elderly patients with intertrochanteric fractures has been found to be safe and effective, with a more limited blood loss, shorter hospital stay, less pain, and greater functional gain versus the conventional technique. ${ }^{104}$ However, a later study ${ }^{105}$ has failed to record fewer transfusion needs or lower mortality after 1 year when comparing treatment in the form of percutaneous compression plating (PCCP) versus dynamic hip screw. Likewise, there appeared to be no differences in clinical effectiveness when comparing PCCP with the proximal femoral nail antirotation technique, though PCCP resulted in lesser blood loss and shorter surgical times. ${ }^{106}$

General, epidural, or spinal anesthesia in elderly patients with hip fracture exerts no influence upon the incidence of delirium or cognitive impairment, duration of stay, patient destination at discharge, or mortality after 1 year. ${ }^{107}$

\section{Prognostic factors and mortality}

Several studies on orthogeriatric care units have shown a reduction in mortality. These studies have also linked a number of prognostic factors with mortality in elderly patients admitted to hospital with hip fractures. Early identification and specific treatment of these factors could help to reduce hip fracture patients mortality. The results of a meta-analysis showed orthogeriatric collaboration to be associated with a significant decrease in in-hospital mortality and mortality over the long term, ${ }^{25}$ with a shorter stay in hospital. No improvements were observed in terms of the incidence of delirium, reductions in surgical delay, or functional recovery.

A comparative study has shown that the presence of orthogeriatric unit reduces the 30-day adjusted mortality rate and mean duration of stay. ${ }^{108}$ The mortality rate and mean stay can be predicted using the Multidimensional Prognostic Index, which contemplates functional, cognitive, nutritional, social, and clinical information and predicts mortality in patients presenting a series of clinical conditions. A study has found high Multidimensional Prognostic Index scores to be associated with longer hospital stays and poorer survival rates. ${ }^{109}$ A retrospective study analyzed the main comorbidities found in patients admitted due to hip fracture and their influence on mortality. A 12-month post-discharge mortality predictive model, based on comorbidities, included patient age, cognitive impairment, and surgical delay, and was able to explain $26 \%$ of the variability in mortality. A second model, based on the complications, included patient age and respiratory complications, and was likewise able to explain $26 \%$ of the variability in mortality. ${ }^{110}$

Another prospective study divided the patients into two age groups ( $85-89$ and $>90$ years). The older group showed greater mortality. The factors associated with mortality after 6 months were severe disability and postoperative delirium. ${ }^{111}$ A retrospective study evaluated the activity of an orthogeriatric care unit of geriatric patients diagnosed with hip fracture between 2004 and 2008. Male sex, Barthel score, heart failure, and cognitive impairment were seen to be associated with an increased mortality risk. With regard to function, $63.7 \%, 77.4 \%$, and $80.1 \%$ of the patients had recovered walking capacity at discharge, 1 month, and 6 months after fracture, respectively. The factors associated with poorer functional recovery included cognitive impairment, functional condition, age, cerebrovascular events, Charlson score, and delirium during hospital admission. ${ }^{112}$

\section{Controversies of the orthogeriatric care model}

Different studies ${ }^{103-115}$ have confirmed that the orthogeriatric care model reduces mean stay and mortality. An analysis ${ }^{116}$ divided the patients with hip fracture into two age groups (65-84 versus $\geq 85$ years). The older group showed greater comorbidity and higher prevalence of cognitive impairment, which were not associated with longer surgical delays, 
though both the length of hospital stay and mortality rate (in-hospital and 30 days and 12 months after discharge) were greater; the percentage of patients entering homes for the elderly after discharge was also higher. The authors concluded that patients aged 85 years or older are high-risk patients and merit specific clinical management. Another retrospective study ${ }^{117}$ compared the results corresponding to 6 months before the start of activities of an orthogeriatric team versus the findings 6 months after the start of such activities. The orthogeriatric team activities resulted in shortened stay and increase in the adoption of secondary fracture prevention measures.

A study has analyzed the changes recorded in a department after the introduction of a clinical pathway in hip fractures. The initiative was found to result in a shortened stay and a lesser probability of complications during hospital admission. ${ }^{118}$ Similar results have been obtained in another study ${ }^{35}$ where the introduction of a multidisciplinary management model with preoperative geriatric assessment and daily geriatric clinical care resulted in an increased percentage of patients operated upon within the first 48 hours and a reduction in hospital stay.

However, these data may be interfered with by circumstances that alter routine care, such as weekends. In this regard, a retrospective study of 2,989 consecutive individuals compared patient care on working days versus care provided on weekends. A significant association with mortality after 30 days was observed in the patients admitted on weekends, despite the absence of greater mortality associated with surgery performed on weekends. ${ }^{119}$

\section{Costs}

A study described the compared cost-utility analysis and orthogeriatric care model versus an interconsultation orthogeriatric department. This paper found orthogeriatric care to offer greater cost-effectiveness since the orthogeriatric care model used $23 \%$ fewer resources per patient $(\$ 14,919$ versus $\$ 19,363$ ) and avoided 0.226 disability-adjusted life years per patient, adding quality-adjusted life years by lowering the cost of institutionalization per patient, with a reduction of mortality after 1 year. ${ }^{120}$ A retrospective cohort study in turn compared orthogeriatric care versus routine trauma care, and found the former to result in mean savings of $\$ 13,737$ per patient, with a decrease in mortality after 12 months. ${ }^{121}$ Lastly, a randomized, prospective intervention study comparing the care provided in an orthogeriatric unit versus the care provided in a traumatology ward with interconsultation geriatric management found the patients treated in the orthogeriatric unit to have a greater probability of starting rehabilitation in the acute cases ward, with greater recovery of walking capacity, earlier surgery, and shorter hospital stay. All these implied an estimated process cost saving of $€ 1,207-€ 1,633$ per patient, including the avoided stays which is an estimated saving of $€ 3,741$ per year. ${ }^{122}$

\section{Future perspectives and lines of research}

It is interesting to mention some recent publications that have evaluated the presence of sarcopenia in patients with hip fracture, in both the acute phase and in the subacute and chronic phases. In a recent study, the prevalence of sarcopenia in patients admitted due to hip fracture was $17.1 \%(12.4 \%$ in males and $18.3 \%$ in females). ${ }^{123}$ In this regard, patients with sarcopenia suffer greater functional loss at discharge. The observed prevalence is low in comparison with the data obtained in other studies. ${ }^{124}$

Another important point requiring consideration is the difference in predicted function and survival after hip fracture in institutionalized patients. A retrospective cohort of 60,111 patients found that $36.2 \%$ of the patients died in the first 180 days after fracture. Of the patients who were not fully dependent before fracture, a total of $53.5 \%$ either died or became totally dependent in the first 180 days - the prognosis being poorer in individuals with severe cognitive impairment, subjects over 90 years of age, patients who had not received surgical treatment for the fracture. ${ }^{125}$

\section{Conclusion}

Orthogeriatric units improve the quality standards of care of geriatric patients with hip fracture, such as survival and functional recovery rates, thereby also reducing the length of stay and costs. Some clinical trials and meta-analyses published over the last 5 years support this evidence. Nevertheless, there are still gaps in knowledge regarding specific clinical issues, such as the best approach to pain, choice of certain surgical procedures, $\mathrm{Hb}$ threshold for blood transfusion, or measures to reduce the incidence of blood transfusions during hospital admission, and the continuity of care in concrete situations, such as cognitive impairment or institutionalization. Future studies are needed to help answer these questions.

\section{Acknowledgment}

The authors would like to thank Juan María de la Cámara de las Heras, librarian and archivist of Hospital Universitario de la Ribera, for his help in carrying out the necessary literature search for this review. 


\section{Author contributions}

Francisco José Tarazona-Santabalbina and Ángel BelenguerVarea carried out a selected keyword search and conceived and designed this study. They selected the articles and drafted the manuscript in collaboration Eduardo Rovira and David Cuesta-Peredó. All authors contributed toward data analysis, drafting and critically revising the paper and agree to be accountable for all aspects of the work.

\section{Disclosure}

The authors report no conflicts of interest in this work.

\section{References}

1. Johnell O, Kanis JA. An estimate of the worldwide prevalence, mortality and disability associated with hip fracture. Osteoporos Int. 2004;15: 897-902.

2. Cooper C, Campion G, Melton LJ. Hip fractures in the elderly: a worldwide projection. Osteoporos Int. 1992;2:285-289.

3. Lauritzen JB, Schwarz P, Lund B, et al. Changing incidence and residual lifetime risk of common osteoporosis-related fractures. Osteoporos Int. 1993;3(3):127-132.

4. Aschkenasy MT, Rothenhaus TC. Trauma and falls in the elderly. Emerg Med Clin North Am. 2006;24(2):413-432.

5. Roche JJ, Wenn RT, Sahota O, et al. Effect of comorbidities and postoperative complications on mortality after hip fracture in elderly people: prospective observational cohort study. BMJ. 2005;331(7529):1374.

6. Morris AH, Zuckerman JD; AAOS Council of Health Policy and Practice, USA. American Academy of Orthopaedic Surgeons. National Consensus Conference on Improving the Continuum of Care for Patients with Hip Fracture. J Bone Joint Surg Am. 2002;84-A(4): 670-674.

7. Bertram M, Norman R, Kemp L, et al. Review of the long-term disability associated with hip fractures. Inj Prev. 2011;17(6):365-370.

8. Braithwaite RS, Col NF, Wong JB. Estimating hip fracture morbidity, mortality and costs. J Am Geriatr Soc. 2003;51(3):364-370.

9. Magaziner J, Hawkes W, Hebel JR, et al. Recovery from hip fracture in eight areas of function. J Gerontol A Biol Sci Med Sci. 2000;55(9) M498-M507.

10. Kannegaard PN, van der Mark S, Eiken P, et al. Excess mortality in men compared with women following a hip fracture. National analysis of comedications, comorbidity and survival. Age Ageing. 2010;39(2): 203-209.

11. Morin S, Lix LM, Azimaee M, et al. Mortality rates after incident nontraumatic fractures in older men and women. Osteoporos Int. 2011; 22(9):2439-2448.

12. Leibson CL, Tosteson AN, Gabriel SE, et al. Mortality, disability, and nursing home use for persons with and without hip fracture: a populationbased study. J Am Geriatr Soc. 2002;50(10):1644-1650.

13. Devas M. Geriatric Orthopaedics. London: Academic Press; 1977.

14. Sabharwal S, Wilson H. Orthogeriatrics in the management of frail older patients with a fragility fracture. Osteoporos Int. 2015;26(10): 2387-2399.

15. Khasraghi FA, Christmas C, Lee EJ, et al. Effectiveness of a multidisciplinary team approach to hip fracture management. J Surg Orthop Adv. 2005;14(1):27-31.

16. Vidan M, Serra JA, Moreno C, et al. Efficacy of a comprehensive geriatric intervention in older patients hospitalized for hip fracture: a randomized, controlled trial. J Am Geriatr Soc. 2005;53(9): 1476-1482.

17. Friedman SM, Mendelson DA, Bingham KW, et al. Impact of a comanaged Geriatric Fracture Center on short-term hip fracture outcomes. Arch Intern Med. 2009;169(19):1712-1717.
18. González-Montalvo JI, Alarcón Alarcón T. Orthogeriatrics in acute patients: to act, but also assess and compare as a way to improve. Rev Esp Geriatr Gerontol. 2014;49(3):101-102.

19. De Rui M, Veronese N, Manzato E, et al. Role of comprehensive geriatric assessment in the management of osteoporotic hip fracture in the elderly: an overview. Disabil Rehabil. 2013;35(9):758-765.

20. Pillai A, Eranki V, Shenoy R, et al. Age related incidence and earl outcomes of hip fractures: a prospective cohort study of 1177 patients. J Orthop Surg Res. 2011;6:5.

21. Wilson H, Harding K, Sahota O. Best practice tariff for hip fracturemaking ends meet. Available from: http://www.bgs.org.uk. Accessed January 13, 2016.

22. Payment by Results Guidance for 2013-2014. Available from: https:// www.gov.uk/government/uploads/system/uploads/attachment_data/ file/214903/Code-of-Conduct-for-Payment-by-Results-in-2013-14.pdf. Accessed January 13, 2016.

23. National Institute for Health and Care Excellence. Quality Standards for Hip Fracture 2012. Available from: http://www.nice.org.uk. Accessed January 13, 2016.

24. Fernandez MA, Griffin XL, Costa ML. Management of hip fracture Br Med Bull. 2015;115(1):165-172.

25. Grigoryan KV, Javedan H, Rudolph JL. Orthogeriatric care models and outcomes in hip fracture patients: a systematic review and meta-analysis. J Orthop Trauma. 2014;28:e49-e55.

26. Della Rocca GJ, Crist BD. Hip fracture protocols: what have we changed? Orthop Clin North Am. 2013;44(2):163-182.

27. Moja L, Piatti A, Pecoraro V, et al. Timing matters in hip fracture surgery: patients operated within 48 hours have better outcomes. A meta-analysis and meta-regression of over 190,000 patients. PLoS One. 2012;7(10):e46175.

28. Vidán MT, Sánchez E, Gracia Y, et al. Causes and effects of surgical delay in patients with hip fracture: a cohort study. Ann Intern Med. 2011; 155(4):226-233.

29. Simunovic N, Devereaux PJ, Sprague S, et al. Effect of early surgery after hip fracture on mortality and complications: systematic review and meta-analysis. CMAJ. 2010;182(15):1609-1616.

30. Marsland D, Chadwick C. Prospective study of surgical delay for hip fractures: impact of an orthogeriatrician and increased trauma capacity. Int Orthop. 2010;34(8):1277-1284.

31. Nicholas JA. Preoperative optimization and risk assessment. Clin Geriatr Med. 2014;30(2):207-218.

32. Hughson J, Newman J, Pendleton RC. Hip fracture management for the hospital-based clinician: a review of the evidence and best practices. Hosp Pract. 2011;39(1):52-61.

33. Wilson H. Multi-disciplinary care of the patient with acute hip fracture: how to optimise the care for the elderly, traumatised patient at and around the time of the fracture to ensure the best short-term outcome as a foundation for the best long-term outcome. Best Pract Res Clin Rheumatol. 2013;27(6):717-730.

34. Pioli G, Barone A, Mussi C, et al; GIOG. The management of hip fracture in the older population. Joint position statement by Gruppo Italiano Ortogeriatria (GIOG). Aging Clin Exp Res. 2014;26(5):547-553.

35. Gupta A. The effectiveness of geriatrician led comprehensive hip fracture collaborative care in a new Acute Hip Unit based in a general hospital setting in the UK. J R Coll Physicians Edinb. 2014;44(1):20-26.

36. Lundström M, Stenvall M, Olofsson B. Symptom profile of postoperative delirium in patients with and without dementia. J Geriatr Psychiatry Neurol. 2012;25(3):162-169.

37. Inouye SK, Westendorp RGJ, Saczynski JS. Delirium in elderly people. Lancet. 2014:911-922.

38. Bellelli G, Mazzola P, Morandi A, et al. Duration of postoperative delirium is an independent predictor of 6-month mortality in older adults after hip fracture. J Am Geriatr Soc. 2014;62(7):1335-1340.

39. Robles MJ, Formiga F, Vidán MT. Delirium prevention and treatment in elderly hip fracture. Med Clínica. 2014;142(8):365-369.

40. Marcantonio ER, Flacker JM, John Wright R, et al. Reducing delirium after hip fracture: a randomized trial. J Am Geriatr Soc. 2001;49(5): $516-522$. 
41. Deschodt M, Braes T, Flamaing J, et al. Preventing delirium in older adults with recent hip fracture through multidisciplinary geriatric consultation. J Am Geriatr Soc. 2012;60(4):733-739.

42. Lundstrom M, Olofsson B, Stenvall M, et al. Postoperative delirium in old patients with femoral neck fracture: a randomized intervention study. Aging Clin Exp Res. 2007;19(3):178-186.

43. Stenvall M, Berggren M, Lundström M, et al. A multidisciplinary intervention program improved the outcome after hip fracture for people with dementia - subgroup analyses of a randomized controlled trial. Arch Gerontol Geriatr. 2012;54(3):e284-e289.

44. Singler K, Biber R, Wicklein S, et al. "N-active": a new comanaged, orthogeriatric ward: observations and prospects. $Z$ Gerontol Geriatr. 2011;44(6):368-374.

45. Colón-Emeric CS. Postoperative management of hip fractures: interventions associated with improved outcomes. Bonekey Rep. 2012; $1: 241$.

46. Seitz DP, Adunuri N, Gill SS, et al. Prevalence of dementia and cognitive impairment among older adults with hip fractures. J Am Med Dir Assoc. 2011;12(8):556-564.

47. Allen J, Koziak A, Buddingh S, et al. Rehabilitation in patients with dementia following hip fracture: a systematic review. Physiother Canada Physiothérapie Canada. 2012;64(2):190-201.

48. Uriz-Otano F, Isidro Uriz-Otano J, Malafarina V. Factors associated with short-term functional recovery in elderly people with a hip fracture. Influence of cognitive impairment. J Am Med Dir Assoc. 2015; 16(3):215-220.

49. Tarazona-Santabalbina FJ, Belenguer-Varea Á, Rovira Daudi E, et al. Severity of cognitive impairment as a prognostic factor for mortality and functional recovery of geriatric patients with hip fracture. Geriatr Gerontol Int. 2015;15(3):289-295.

50. Morghen S, Gentile S, Ricci E, et al. Rehabilitation of older adults with hip fracture: cognitive function and walking abilities. J Am Geriatr Soc. 2011;59(8):1497-1502.

51. Wu Q, Liu J, Gallegos-Orozco JF, et al. Depression, fracture risk, and bone loss: a meta-analysis of cohort studies. Osteoporos Int. 2010;21(10): 1627-1635.

52. Dubljanin Raspopović E, Marić N, Nedeljković U, et al. Do depressive symptoms on hospital admission impact early functional outcome in elderly patients with hip fracture? Psychogeriatrics. 2014;14(2): 118-123.

53. Guerini F, Morghen S, Lucchi E, et al. Depressive symptoms and one year mortality among elderly patients discharged from a rehabilitation ward after orthopaedic surgery of the lower limbs. Behav Neurol. 2010; 23(3):117-121.

54. Morghen S, Bellelli G, Manuele S, et al. Moderate to severe depressive symptoms and rehabilitation outcome in older adults with hip fracture. Int J Geriatr Psychiatry. 2011;26:1136-1143.

55. Phillips AC, Upton J, Duggal NA, Carroll D, Lord JM. Depression following hip fracture is associated with increased physical frailty in older adults: the role of the cortisol: dehydroepiandrosterone sulphate ratio. BMC Geriatr. 2013;13:60.

56. Neighbour C. Improving bowel care after surgery for hip fracture. Nurs Older People. 2014;26(10):16-22.

57. Trads M, Pedersen PU. Constipation and defecation pattern the first 30 days after hip fracture. Int J Nurs Pract. 2015;21(5):598-604.

58. Oral laxative use pre- and post-hip fracture or other emergency orthopedic surgery: a review of the guidelines - PubMed - NCBI [Internet]. [cited January 28, 2016 Jan 28]. Available from: http://www.ncbi.nlm. nih.gov/pubmed/26180883. Accessed May 31, 2016

59. Drevet S, Bioteau C, Mazière S, et al. Prevalence of protein-energy malnutrition in hospital patients over 75 years of age admitted for hip fracture. Orthop Traumatol Surg Res. 2014;100(6):669-674.

60. Koren-Hakim T, Weiss A, Hershkovitz A, et al. The relationship between nutritional status of hip fracture operated elderly patients and their functioning, comorbidity and outcome. Clin Nutr. 2012;31(6): 917-921.
61. Bell JJ, Bauer JD, Capra S, et al. Quick and easy is not without cost: implications of poorly performing nutrition screening tools in hip fracture. J Am Geriatr Soc. 2014;62(2):237-243.

62. Eneroth M, Olsson U-B, Thorngren K-G. Nutritional supplementation decreases hip fracture-related complications. Clin Orthop Relat Res. 2006; 451:212-217.

63. Botella-Carretero JI, Iglesias B, et al. Effects of oral nutritional supplements in normally nourished or mildly undernourished geriatric patients after surgery for hip fracture: a randomized clinical trial. JPEN J Parenter Enteral Nutr. 2008;32(2):120-128.

64. Duncan DG, Beck SJ, Hood K, et al. Using dietetic assistants to improve the outcome of hip fracture: a randomised controlled trial of nutritional support in an acute trauma ward. Age Ageing. 2006;35(2): $148-153$

65. Hoekstra JC, Goosen JHM, de Wolf GS, et al. Effectiveness of multidisciplinary nutritional care on nutritional intake, nutritional status and quality of life in patients with hip fractures: a controlled prospective cohort study. Clin Nutr. 2011;30(4):455-461.

66. Pimlott BJ, Jones CA, Beaupre LA, et al. Prognostic impact of preoperative albumin on short-term mortality and complications in patients with hip fracture. Arch Gerontol Geriatr. 2011;53(1):90-94

67. Liu H-Y, Tseng M-Y, Li H-J, et al. Comprehensive care improves physical recovery of hip-fractured elderly Taiwanese patients with poor nutritional status. J Am Med Dir Assoc. 2014;15(6):416-422.

68. Liu M, Yang J, Yu X, et al. The role of perioperative oral nutritional supplementation in elderly patients after hip surgery. Clin Interv Aging. 2015;10:849-858

69. Altman KW, Yu G-P, Schaefer SD. Consequence of dysphagia in the hospitalized patient: impact on prognosis and hospital resources. Arch Otolaryngol Head Neck Surg. 2010;136(8):784-789.

70. Love AL, Cornwell PL, Whitehouse SL. Oropharyngeal dysphagia in an elderly post-operative hip fracture population: a prospective cohort study. Age Ageing. 2013;42(6):782-785

71. Adunsky A, Nenaydenko O, Koren-Morag N, et al. Perioperative urinary retention, short-term functional outcome and mortality rates of elderly hip fracture patients. Geriatr Gerontol Int. 2015;15(1): 65-71.

72. Maggi S, Minicuci N, Langlois J, et al. Prevalence rate of urinary incontinence in community-dwelling elderly individuals: the Veneto study. J Gerontol A Biol Sci Med Sci. 2001;56(1):M14-M18.

73. Luk JKH, Chiu PKC, Tam S, et al. Relationship between admission albumin levels and rehabilitation outcomes in older patients. Arch Gerontol Geriatr. 2011;53(1):84-89.

74. Sørbye LW, Grue EV. Hip fracture and urinary incontinence - use of indwelling catheter postsurgery. Scand J Caring Sci. 2013;27(3): 632-642.

75. Palmer $\mathrm{MH}$, Baumgarten $\mathrm{M}$, Langenberg $\mathrm{P}$, et al. Risk factors for hospital-acquired incontinence in elderly female hip fracture patients. J Gerontol A Biol Sci Med Sci. 2002;57(10):M672-M677.

76. Candel-Parra E, Córcoles-Jiménez MP, Del Egido-Fernández MA, et al. Independence in activities of daily living 6 months after surgery in previously independent elderly patients with hip fracture caused by a fall. Enfermería Clínica. 2008;18(6):309-316.

77. Alarcón T, González-Montalvo JI, Gotor P, et al. Activities of daily living after hip fracture: profile and rate of recovery during 2 years of follow-up. Osteoporos Int. 2011;22(5):1609-1613.

78. Parkinson L, Chiarelli P, Byrne J, et al. Continence promotion for older hospital patients following surgery for fractured neck of femur: pilot of a randomized controlled trial. Clin Interv Aging. 2007;2(4): 705-714.

79. Lindholm C, Sterner E, Romanelli M, et al. Hip fracture and pressure ulcers - the Pan-European Pressure Ulcer Study - intrinsic and extrinsic risk factors. Int Wound J. 2008;5(2):315-328.

80. Rodriguez-Fernandez P, Adarraga-Cansino D, Carpintero P. Effects of delayed hip fracture surgery on mortality and morbidity in elderly patients. Clin Orthop Relat Res. 2011;469(11):3218-3221. 
81. Ireland AW, Kelly PJ, Cumming RG. Total hospital stay for hip fracture: measuring the variations due to pre-fracture residence, rehabilitation, complications and comorbidities. BMC Health Serv Res. 2015; $15: 17$.

82. Neuman MD, Archan S, Karlawish JH, et al. The relationship between short-term mortality and quality of care for hip fracture: a meta-analysis of clinical pathways for hip fracture. J Am Geriatr Soc. 2009;57(11): 2046-2054

83. Donnelly J, Winder J, Kernohan WG, et al. An RCT to determine the effect of a heel elevation device in pressure ulcer prevention post-hip fracture. J Wound Care. 2011;20(7):314-318.

84. Rich SE, Shardell M, Hawkes WG, et al. Pressure-redistributing support surface use and pressure ulcer incidence in elderly hip fracture patients. J Am Geriatr Soc. 2011;59(6):1052-1059.

85. Adunsky A, Mizrahi EH, Kaplan A, et al. Elevated blood urea, independent of glomerular filtration rate (GFR), confers increased risk of adverse functional outcome in elderly hip fracture patients. Arch Gerontol Geriatr. 2011;53(2):e174-e178.

86. Carson JL, Terrin ML, Noveck H, et al. Liberal or restrictive transfusion in high-risk patients after hip surgery. $N$ Engl J Med. 2011;365(26): 2453-2462.

87. Gregersen M, Borris LC, Damsgaard EM. Postoperative blood transfusion strategy in frail, anemic elderly patients with hip fracture: the TRIFE randomized controlled trial. Acta Orthop. 2015;86(3): 363-372.

88. Brunskill SJ, Millette SL, Shokoohi A, et al. Red blood cell transfusion for people undergoing hip fracture surgery. Cochrane Database Syst Rev. 2015;4:CD009699.

89. Yang Y, Li H, Li B, et al. Efficacy and safety of iron supplementation for the elderly patients undergoing hip or knee surgery: a metaanalysis of randomized controlled trials. J Surg Res. 2011;171(2): e201-e207.

90. Colon-Emeric C, Kuchibhatla M, Pieper C, et al. The contribution of hip fracture to risk of subsequent fractures: data from two longitudinal studies. Osteoporos Int. 2003;14(11):879-883.

91. Halperin E, Engel T, Sherman S, et al. Low admission Norton scale scores are associated with falls long after rehabilitation in the elderly with hip fractures. Clin Interv Aging. 2012;7:431-436.

92. Gold A, Sever R, Lerman Y, et al. Admission Norton scale scores (ANSS) and postoperative complications following hip fracture surgery in the elderly. Arch Gerontol Geriatr. 2012;55(1):173-176.

93. Shen S-H, Huang K-C, Tsai Y-H, et al. Risk analysis for second hip fracture in patients after hip fracture surgery: a nationwide populationbased study. J Am Med Dir Assoc. 2014;15(10):725-731.

94. Lönnroos E, Kautiainen H, Karppi P, et al. Incidence of second hip fractures. A population-based study. Osteoporos Int. 2007;18(9): 1279-1285.

95. Deschodt M, Flamaing J, Haentjens $P$, et al. Impact of geriatric consultation teams on clinical outcome in acute hospitals: a systematic review and meta-analysis. BMC Med. 2013;11:48.

96. Wang CY, Graham JE, Karmarkar AM, et al. FIM motor scores for classifying community discharge after inpatient rehabilitation for hip fracture. PM R. 2014;6(6):493-497.

97. Prestmo A, Hagen G, Sletvold O, et al. Comprehensive geriatric care for patients with hip fractures: a prospective, randomised, controlled trial. Lancet. 2015;385(9978):1623-1633.

98. Kamel HK, Iqbal MA, Mogallapu R, et al. Time to ambulation after hip fracture surgery: relation to hospitalization outcomes. J Gerontol A Biol Sci Med Sci. 2003;58(11):1042-1045.

99. Siu AL, Penrod JD, Boockvar KS, et al. Early ambulation after hip fracture: effects on function and mortality. Arch Intern Med. 2006; 166(7):766-771.

100. Oldmeadow LB, Edwards ER, Kimmel LA, et al. No rest for the wounded: early ambulation after hip surgery accelerates recovery. ANZ J Surg. 2006;76(7):607-611.
101. Taraldsen K, Sletvold O, Thingstad P, et al. Physical behavior and function early after hip fracture surgery in patients receiving comprehensive geriatric care or orthopedic care - a randomized controlled trial. J Gerontol A Biol Sci Med Sci. 2014;69(3):338-345.

102. Macaulay W, Pagnotto MR, Iorio R, et al. Displaced femoral neck fractures in the elderly: hemiarthroplasty versus total hip arthroplasty. J Am Acad Orthop Surg. 2006;14(5):287-293.

103. Ho M, Garau G, Walley G, et al. Minimally invasive dynamic hip screw for fixation of hip fractures. Int Orthop. 2009;33(2): $555-560$.

104. Cheng T, Zhang G, Zhang X. Review: minimally invasive versus conventional dynamic hip screw fixation in elderly patients with intertrochanteric fractures: a systematic review and meta-analysis. Surg Innov. 2011;18(2):99-105.

105. Gaddi D, Piarulli G, Angeloni A, et al. Gotfried percutaneous compression plating (PCCP) versus dynamic hip screw (DHS) in hip fractures: blood loss and 1-year mortality. Aging Clin Exp Res. 2014; 26(5):497-503.

106. Guo Q, Shen Y, Zong Z, et al. Percutaneous compression plate versus proximal femoral nail anti-rotation in treating elderly patients with intertrochanteric fractures: a prospective randomized study. J Orthop Sci. 2013;18(6):977-986.

107. Ilango S, Pulle RC, Bell J, et al. General versus spinal anaesthesia and postoperative delirium in an orthogeriatric population. Australas J Ageing. 2015

108. Zeltzer J, Mitchell RJ, Toson B, et al. Orthogeriatric services associated with lower 30-day mortality for older patients who undergo surgery for hip fracture. Med J Aust. 2014;201(7):409-411.

109. Angleman SB, Santoni G, Pilotto A, et al; MPI_AGE Project Investigators. Multidimensional prognostic index in association with future mortality and number of hospital days in a population-based sample of older adults: results of the EU funded MPI_AGE Project. PLoS One. 2015;10(7): $\mathrm{e} 0133789$.

110. Henderson CY, Ryan JP. Predicting mortality following hip fracture: an analysis of comorbidities and complications. Ir J Med Sci. 2015;184(3): 667-671.

111. Mazzola P, Bellelli G, Broggini V, et al. Postoperative delirium and pre-fracture disability predict 6-month mortality among the oldest old hip fracture patients. Aging Clin Exp Res. 2015;27(1):53-60.

112. Tarazona-Santabalbina FJ, Belenguer-Varea A, Rovira-Daudi E, et al. Early interdisciplinary hospital intervention for elderly patients with hip fractures: functional outcome and mortality. Clinics (Sao Paulo). 2012;67(6):547-556.

113. Adunsky A, Lerner-Geva L, Blumstein T, et al. Improved survival of hip fracture patients treated within a comprehensive geriatric hip fracture unit, compared with standard of care treatment. $J$ Am Med Dir Assoc. 2011;12(6):439-444.

114. Leung AH, Lam TP, Cheung WH, et al. An orthogeriatric collaborative intervention program for fragility fractures: a retrospective cohort study. J Trauma. 2011;71(5):1390-1394.

115. Bhattacharyya R, Agrawal Y, Elphick H, et al. A unique orthogeriatric model: a step forward in improving the quality of care for hip fracture patients. Int J Surg. 2013;11(10):1083-1086.

116. Moon A, Gray A, Deehan D. Neck of femur fractures in patient's aged more than 85 years-are they a unique subset? Geriatr Orthop Surg Rehabil. 2011;2(4):123-127.

117. Gregersen M, Mørch MM, Hougaard K, et al. Geriatric intervention in elderly patients with hip fracture in an orthopedic ward. J Inj Violence Res. 2012;4(2):45-51.

118. Suhm N, Kaelin R, Studer P, et al. Orthogeriatric care pathway: a prospective survey of impact on length of stay, mortality and institutionalisation. Arch Orthop Trauma Surg. 2014;134(9): $1261-1269$

119. Thomas CJ, Smith RP, Uzoigwe CE, et al. The weekend effect: shortterm mortality following admission with a hip fracture. Bone Joint $J$. 2014;96-B(3):373-378. 
120. Ginsberg G, Adunsky A, Rasooly I. A cost-utility analysis of a comprehensive orthogeriatric care for hip fracture patients, compared with standard of care treatment. Hip Int. 2013;23(6):570-575.

121. Della Rocca GJ, Moylan KC, Crist BD, et al. Comanagement of geriatric patients with hip fractures: a retrospective, controlled, cohort study. Geriatr Orthop Surg Rehabil. 2013;4:10-15.

122. González Montalvo JI, Gotor Pérez P, Martín Vega A, et al. The acute orthogeriatric unit. Assessment of its effect on the clinical course of patients with hip fractures and an estimate of its financial impact. Rev Esp Geriatr Gerontol. 2011;46(4):193-199.
123. González-Montalvo JI, Alarcón T, Gotor P, et al. Prevalence of sarcopenia in acute hip fracture patients and its influence on short-term clinical outcome. Geriatr Gerontol Int. Epub 2015 Sep 3.

124. Ho AW, Lee MM, Chan EW, et al. Prevalence of pre-sarcopenia and sarcopenia in Hong Kong Chinese geriatric patients with hip fracture and its correlation with different factors. Hong Kong Med J. 2016;22(1):23-29.

125. Neuman MD, Silber JH, Magaziner JS, et al. Survival and functional outcomes after hip fracture among nursing home residents. JAMA Intern Med. 2014;174(8):1273-1280.

\section{Publish your work in this journal}

Clinical Interventions in Aging is an international, peer-reviewed journal focusing on evidence-based reports on the value or lack thereof of treatments intended to prevent or delay the onset of maladaptive correlates of aging in human beings. This journal is indexed on PubMed Central, MedLine,

\section{Dovepress}

CAS, Scopus and the Elsevier Bibliographic databases. The manuscript management system is completely online and includes a very quick and fair peer-review system, which is all easy to use. Visit http://www.dovepress. com/testimonials.php to read real quotes from published authors. 